of a butterfly which the Mantis patiently waits for, perched on the top of some conspicuous head of flowers.

Simla, January 17

E. R. JOHNSON

\section{Fabry's Comet}

ON the 6 th inst., with a power of 38 on a $4 \frac{1}{4}$-inch refractor, I observed that this comet had a distinct, though very faint, tail, at a position-angle of about $85^{\circ}$; length $13 \frac{1}{2}^{\prime}$. The radius of the coma was about $3^{\prime}$. I thought I could see the tail on the Ist inst., but was not quite sure of it then. The comet's spectrum strikes me as less distinct than is the case with most comets. On the Ist inst. I could only see two bright lines (or bands) certainly; and the less refrangible of these was very faint. I suspected a third band towards the more refrangible end of the spectrum,

Sunderland, February I3

T. W. BACK HoUse

\section{Mist.Bow}

ON the Wiltshire Downs, near Marlborough, at about 4 o'clock on February IO, I observed a white mist-bow, in position and shape resembling the rainbow, but pure white, and the arc was of considerable width throughout, estimated at $5^{\circ}-10^{\circ}$, altitude of the sun $15^{\circ}-20^{\circ}$, altitude of the summit of the bow $35^{\circ}-45^{\circ}$. The wind was slight, and there was a frost at the time, and a thick deposit of rime on the trees, \&c. Has this been observed elsewhere or explained? Is the phenomenon due to the superposition of coloured bows, or to the polarisation of the semicrystallised vapour composing the fog?

\section{Movement of Telegraph-Wires}

Thine can be no doubt that Mr. Mountford Deeley correctly attributes the rotatory oscillation of the wires during frost to the air-current acting upon a "wing" of ice-spicules. I described this phenomenon in Science Gossip, 1874, p. 254, and explained the cause of it in NATURE, vol. xxiii. p. 338 .

Birstal Hill, Leicester

F. T. MotT

\section{HENRY BRADSHAW}

U NFORTUNATELY it far too often happens that there seems to be an impassable gulf fixed between the man of letters and the man of science, which hinders the one not only from partaking in, but even from appreciating, the ideas, the objects, and the methods of the other. There is no need, especially here, to impute blame to either; but when a man of letters is found who, modestly making not the least pretension to scientific knowledge, yet sympathises deeply with the man of science, some acknowledgment of the fact seems to be due. Such an instance there was in Mr. Henry Bradshaw, Senior Fellow of King's College, and Librarian of the University, whose sudden removal Cambridge is now mourning. Of his literary ability, his bibliographical accuracy, his mastery of one important period of English poetry, and his knowledge of early printed books, this is not the place to speak. Justice to those qualities doubtless is being, or will in due time be, rendered by other writers, better fitted to pronounce an opinion upon them. But here may be appropriately recorded the enthusiasm -for no other word will suit-with which he at all times entered into and aided inquiries, investigations, and researches that most men in his position would have considered to lie entirely outside of their own, and as such to be without any dereliction of duty disregarded. His time, his energy, and his varied attaimments were always at the disposal of any member of the University, whose servant, in the highest sense of the word, he rejoiced to be. But there was no need for any one to be a member of the University to obtain his help. Accessible at all times to all who sought him, the asking of a simple question was a sufficient introduction, and whether that introduction was only the prelude to an acquaintanceship which might speedily ripen into a friendship depended far more on the person who asked it than on himself. By the younger members of the University to whom he was known, and the number of them was vast, he was regarded with feelings of affection, that it would seem almost exaggeration to describe, and his influence over them, always tending towards the highest ends, was proportionately great. But here it is more fitting to dwell upon the active sympathy he showed with students of biology. His great intimacy with the late Mr. G. R. Crotch had led him to take an extreme interest in the literature of systematic zoology, and particularly in the precision which is required of those who pursue the branch of it relating to the Coleoptera, not that Mr. Bradshaw must be supposed to have had any knowledge of the subject. It was simply the method of accurate work which excited his admiration, and that method, he has more than once told the present writer, had largely influenced his own bibliographical investigations, the high value set upon which must be told by those whom they concern. Never taking offence, wholly free from pride, always ready to put the best construction on every man's conduct, catholic in all his feelings, Mr. Bradshaw passed away in his College rooms, apparently without any suffering, on the night of the roth or morning of the IIth of this month-an end to be envied by most men.

A. $\mathrm{N}$

\section{THE COAL-DUST QUESTYON}

I $N$ the last paragraph of my letter to NATURE (Dec. $3 \mathrm{I}$, p. 197), I stated that those who, having investigated the question of the influence of coal-dust in colliery explo. sions, had come to the conclusion that coal-dust is not, as a rule, the principal agent in an explosion occurring in a dry and dusty mine, appear to have omitted to take one important element of the case into consideration ; and in saying so I implied that, if they had not made this omission, their conclusions in this respect would probably have been more in accordance with my own.

All the important experiments with coal-dust on a large scale have been made in wooden boxes or galleries of greater or less length, open at one end and closed at the other. The ignition or explosion has ustually been begun at or near the closed end, and been propagated towards the open end, driving part of the contents of the gallery out into the air in front of it.

Certain conclusions in regard to colliery explosions have been drawn from the results obtained on this small scale which appear to ignore the fact that the conditions here prevailing are far less favourable to the propagation of the coal-dust flame than those which obtain in a mine at the instant an explosion is sweeping through it. For, it is obvious that in the former case the air is practically at constant pressure while the explosion lasts, whereas in the latter case it is practically at constant volume during the same period. But as the amount of heat required to raise the mixture of air and coal-dust to the temperature of ignition in the first case is greater than that required to effect the same result in the second case in the ratio of I $4 \mathrm{I}$ to $\mathrm{I}$, it follows that an explosion having been once begun in either case will be propagated much more rapidly and surely in the mine than in the apparatus. Thus it is that a kind of coal-dust which produces comparatively feeble results in the apparatus may give rise to very disastrous consequences in the mine.

An illustration of this difference of behaviour under the two sets of conditions has been furnished by the dust of Camphausen Colliery in Germany. When subjected to the experimental test in the large apparatus at Neunkirchen, already described in these pages, it was found to be far down the list in point of relative danger, and was pronounced to be, like most of the other dusts in the same list above and below it, of a comparatively harmless. 
nature. But when an explosion subsequently occurred in the mine, and traversed the whole length and breadth of the workings, which were known to be practically free from fire-damp at the time, producing the most disastrous effects, the fallacy of the conclusions drawn from the experimental results was rendered abundantly evident.

In the whole of my papers on this subject, and most pointedly in my last article on coal-dust expiosions published in Iron, in the year 1878 , I have carefully indicated that a difference was to be expected in the behaviour of dust ignited under the two conditions named. It has therefore been with feelings of considerable surprise that I have observed members of the French, English, and German Mining Commissions, and others who have investigated this subject since the publication of my first paper, one after the other pronounce some very decided opinions as to the relatively subordinate part which coaldust plays in a colliery explosion, while at the same time they were neglecting to take into account this very simple and yet all-important element.

W. GaLlOWAY

VESUVIAN ERUPTION OF FEBRUARY 4, I886

THE rent that was formed on May 2, 1885, in the upper part of the great cone (NATURE, vol. xxxii. p. 55) gave issue to lava until December 25. A small quantity again issued between January 2 and January 5, I886, after which no more made its appearance till this new outburst. In consequence of the rise of level of the magma in the chimney, the cone of eruption has grown very much during the last month.

On February 4, at about 8 p.m., lava broke forth at the foot of the old crater ring of $188 \mathrm{I}-2$ at a point bearing from the main vent about $10^{\circ} \mathrm{W}$. of $\mathrm{N}$., traversed the crater plain, which is here very narrow, in a somewhat oblique direction, and ran down the slope of the cone between north and north-north-east. 'The lava soon reached the foot of the cone, but even up till midday today, when I left the mountain, it had not yet commenced to cross the Atrio del Cavallo. The eruption took place from probably the same dyke that gave rise to that of January 9, 1884.

To-day, February 6 , the lava bubbles up like a spring at the foot of a hill, and flows for some distance in a kind of trough which it has raised on each side of itself above the level of the crater plains. After a short distance it enters one of its own tunnels to reappear again at some distance. It was very interesting to watch its welling, and from time to time the bursting of a steam bubble as big as a bucket, which would throw up splashes against the imperfect arch at the immediate exit. These splashes partly adhered to the roof and partly fell, drawing out the suspended portion into irregular strings, illustrating the formation of the stalactitic lava that is so common in lava fumaroles.

The chloride crusts in the neighbourhood were uncommonly rich in copper, so that my boot-nails were thickly plated with that metal.

The lava makes its appearance at about 100 yards from its entrance in the tunnel near the main spring, although it is now divided into two streams. The eastern, which is the largest, is I metre broad; I plunged a stick in to the depth of I metre, but the shortness of the stick and the great heat prevented me from touching the bottom. The current ran at the rate of I metre per 6 seconds, which, making allowance for viscous drag at the edges and bottom, will give an output of at least 360 cubic metres per hour, or at least 17,280 cubic metres during the 48 hours up to 8 o'clock this evening. The more western stream was 50 centimetres broad, over $I^{\circ} 20$ metres deep (as far as I could reach with my stick), and flowed at the rate of $I$ metre in 8 seconds. Giving a loss of 2 seconds of speed from drag at sides and bottom, we have an output, for 48 hours, of 10,368 cubic metres.
The two streams together would, therefore, have afforded, since the commencement of the eruption, 27,648 cubic metres.

As the altitude of the lateral ot:tlet is much more than that of May 2, both on the night of the eruption and the following one, the volcano showed the first stage of activity as judged by the appearance of the main vent.

This winter the mountain has been covered by snow several times, and to-day it extends down nearly to the level of the Observatory. During our ascent we had to walk through a stratum of about 8 inches, though much thicker in the drifts. Two-thirds of the crater and part of the cone of eruption were also covered.

I should have sent news yesterday, but, on attempting an ascent, I was driven back by wind, rain, and mist.
Naples, February 6
H. J. JOHNSTON-LAvis

\section{TIDAL FRICTION AND THE EVOLUTION OF $A$ SATELLITE}

A PAPER by Mr. James Nolan has recently appeared which is devoted to an adverse criticism of my views concerning the effects of tidal friction as a factor in the evolution of the moon and earth.

The title of the pamphlet, "Darwin's Theory of the Genesis of the Moon," I shows, I think, that the author has misconceived the scope of my work. It was not supposed that the investigation threw light on the actual mode of genesis of the moon, but was rather applicable to the subsequent history of the moon and earth. Mr. Nolan attributes to me views as to the condition of the moon immediately after her birth which do not appear a just interpretation of my writings, and although it might have been well to use more guarded expressions in some passages, the justice of his condemnation of the whole theory cannot be admitted. He sums up his case by the three following propositions:-

"(I) That the moon could not have existed bodily so near the earth as the greatest initial distance fixed.

"(2) That in any form possible there she could not have receded by the agency assigned-tidal friction.

"(3) That, if a modification be made by allowing her to have separated at a greater radius than that corresponding to a period between 2 and 4 hours, the moon would be no longer traceable to the earth's present surface on which condition the theory has been founded."

The first of these propositions is interesting, and I have to thank him for drawing my attention to it.

When a small satellite revolves about a planet with a certain proximity, the sum of the centrifugal and tidal forces may be such as to overbalance the gravitation towards the centre of the satellite. When this is the case, the satellite cannot exist as a single mass. The complete solution of the problem, concerning which $\mathrm{Mr}$. Nolan adduces certain elementary considerations, is of extreme difficulty. At present I do not wish to go into this question, but shall consider the point on another occasion. It may, however, be admitted that the moon could not subsist as a single continuous body with its surface in contact with the earth.

On p. 4 he quotes a passage from the abstract of one of the papers (Proc. R.S., No. 200, 1879), which must be surrendered ; it is as follows:-

"The coincidence is noted in the paper that the shortest period of revolution of a fluid mass of the same mean density as the earth, which is consistent with an eliipsoidal form of equilibrium is 2 hours and 24 minutes ; and if the moon were to revolve about the earth with this periodic time, the surfaces of the two bodies would be almost in contact with one another."

Now, since 1879 it has been shown by Sir William Thomson that the ellipsoidal form referred to could not

I Geo. Robertson and Co., Melbourne, Sydney, Adelaide, and Brisbane, 1885. Pp. 16. 